\title{
IMPLICACIONES CIVILES Y PENALES EN LAS QUE INCURRE EL REVISOR FISCAL POR LA MODIFICACIÓN DE LA OPINIÓN EN SU DICTAMEN *
}

\section{Civil and criminal implications incurred by the fiscal auditor for the modification of the opinion in his report}

\author{
Ludivia Hernández Aros**, Rodrigo Alberto Plazas Estepa*** \\ Laura Constanza Gallego Cossio ${ }^{* * * *}$, Fernando Gutiérrez Portela*****
}

Recepción: 23 de julio de 2020. Aceptación: 23 de febrero de 2021.

DOI: http://dx.doi.org/10.21017/Rev.Repub.2021.v30.a101

\section{RESUMEN}

Actualmente en el ejercicio de la revisoría fiscal, el contador se enfrenta a diferentes situaciones que afectan o modifican su opinión en un dictamen ya

* Artículo derivado de los proyectos de investigación «Diseño de estrategias que inciden en los mecanismos de recolección de pruebas en una auditoría forense que propendan por mitigar el riesgo en las organizaciones» asociado al grupo PLANAUDI y AQUA, adscrito al Centro de Investigaciones del programa de Contaduría Pública de la Universidad Cooperativa de Colombia, sede Ibagué, y del proyecto «Análisis jurídico de la figura del revisor fiscal en los últimos tiempos en el ejercicio profesional en las organizaciones empresariales» del Grupo Derecho Laboral Económico y Estado de la Corporación Universitaria Republicana.

** Magíster en Auditoría y Gestión Empresarial de la Universidad UNINI, Puerto Rico. Especialista en Revisoría Fiscal y Control de Gestión de la Universidad Cooperativa de Colombia. Profesora Investigadora de la Facultad de Contaduría Pública de la Universidad Cooperativa de Colombia, sede Ibagué-Espinal, Colombia, Grupo de investigación PLANAUDI y SINERGIA UCC. Correo electrónico: ludivia.hernandez@campusucc.edu.co

*** Doctorando en Derecho de la Universidad de Buenos Aires. Máster en Derecho Comercial y Abogado de la Universidad Sergio Arboleda. Director y docente del Centro de Investigaciones de la Corporación Universitaria Republicana, investigador sénior del Ministerio de Ciencia, Tecnología e Innovación de Colombia. Correo electrónico: rodrigoplazas@urepublicana.edu.co

**** Doctora en Administración de la Universidad Simón Bolívar de Barranquilla. Profesora investigadora de la Universidad Cooperativa de Colombia, sede Ibagué-Espinal. Grupo de investigación PLANAUDI. Correo electrónico: laura.gallego@campusucc.edu.co

***** Candidato a Doctor en Ingeniería de la Universidad Autónoma de Bucaramanga, UNAB. Magíster en Software Libre, Profesor investigador del programa de Ingeniería de Sistemas e Ingeniería Civil de la Universidad Cooperativa de Colombia (UCC), sede Ibagué-Espinal. Integrante del Grupo de Investigación AQUA de la UCC, IbaguéEspinal. Correo electrónico: fernando.gutierrez@campusucc.edu.co 
divulgado; esto genera incertidumbre a los grupos de interés, exponiéndose a un problema jurídico de corte civil o penal. Es así como el presente artículo analiza las implicaciones civiles y penales en las que incurre el revisor fiscal por la modificación de la opinión en su dictamen. Desde la perspectiva metodológica, la investigación es analítica. Se parte de una indagación de la normativa para el ejercicio de la revisoría fiscal en Colombia, luego se analizan las implicaciones civiles y penales al modificar una opinión en su dictamen de acuerdo con el Código Penal, el Código Civil, la Ley 43 de 1990, el Código de Comercio y el sustento legal. Los resultados muestran que, para el revisor fiscal, cuando se le compruebe dolo producto de un cambio de opinión, se establece un valor económico que será determinado por un juzgado, el cual va desde 50 hasta 50.000 SMLV, dependiendo del daño ocasionado y de acuerdo con la conducta punible dolosa, culposa o preterintencional, con una pena entre uno (1) y treinta (30) años de prisión según el daño ocasionado hacia los stakeholders afectados.

Palabras clave: implicaciones civiles, implicaciones penales, revisoría fiscal, dictamen del revisor fiscal.

\section{ABSTRACT}

Currently in the exercise of the fiscal revision, the accountant faces different situations that affect or modify his opinion in an already disclosed report, this generates uncertainty to the interest groups, exposing himself to a legal problem of civil or criminal court. Thus, this article analyzes the civil and criminal implications incurred by the fiscal auditor for the modification of the opinion in his report. From the methodological perspective, the research is analytical. It begins with an investigation of the regulations for the exercise of the statutory review in Colombia, and then analyzes the civil and criminal implications of modifying an opinion in its ruling in accordance with the criminal code, civil code, law 43 of 1990, commercial code, and legal support. The results show that when the fiscal auditor is found to have committed fraud as a result of a change of opinion, an economic value is established that will be determined by a court ranging from 50 to 50,000 SMLV, depending on the damage caused and according to whether the conduct is punishable as intentional, negligent or premeditated, with a penalty of between one (1) and thirty (30) years in prison, depending on the damage caused to the affected stakeholders.

Keywords: Civil implications, criminal implications, fiscal revision, fiscal auditor's report. 


\section{INTRODUCCIÓN}

La figura del revisor fiscal ha sido cuestionada en los últimos tiempos debido al papel que desempeña en el ejercicio profesional en las organizaciones que han mostrado cifras de estados financieros que no corresponden a la realidad. En efecto, algunos profesionales se han prestado para mostrar dictámenes o informes manipulados, reflejando la falta de práctica del código de ética contemplado en la Ley 43 de 1990 y el Decreto 2270 del 2019. Estas situaciones son analizadas por los miembros de la Junta Central de Contadores que investigan a través de su tribunal más de 1.177 expedientes y en los últimos 10 años han sancionado a más de 604 revisores fiscales (Revista Dinero, 2017).

La modificación de la opinión, una vez se tenga que realizar, será atendiendo a las Normas Internacionales de Auditoría (NIA), específicamente NIA 705: a) la primera situación que suscita la modificación del informe - en el apartado «opinión» - se denomina opinión con salvedades, b) la segunda se denomina opinión desfavorable o adversa, y finalmente c) opinión de negación de la opinión o abstención, generadas por incorrecciones materiales detectadas o por no obtener evidencia suficiente y válida que soporte el dictamen; modificación que debe ser analizada, según los hechos que hicieron que esta nueva opinión se genere, con el fin de establecer su responsabilidad jurídica, sea civil o penal.

En este orden de ideas, existen dos circunstancias que se generan para que se cambie esta opinión: a) cuando el revisor fiscal en su informe a la asamblea expuso su opinión y las razones por las cuales se basó en ella, y al conocer en detalle las circunstancias se toman medidas que cambian la situación inicial atendiendo a las recomendaciones y observaciones expuestas en el informe y b) cuando el revisor fiscal al realizar las pruebas no se percató de algunos hallazgos significativos que afectan gravemente la situación financiera de la empresa, pero después de emitido su dictamen observó tal situación.

Por su parte, al revisor fiscal le implica una responsabilidad sobre este dictamen que deberá cambiar y que generará consecuencias analizadas por la asamblea o junta de socios, el Estado y demás entidades que se vieron afectadas. En este contexto, la palabra responsabilidad expresa que «Solo quienes son plenamente capaces pueden asumir derechos y obligaciones y, correlativamente, son los únicos de quienes se espera que asuman las consecuencias de sus propios hechos» (Bermúdez Gómez, 2020); responsabilidad que el revisor fiscal tiene en su función hacia terceros, en búsqueda de ayudar a las organizaciones a operar de una manera socialmente responsable, situación que va de la mano con lo expresado por la ISO 26000 (Organización Internacional de Estandarización, ISO 26000, 2010). 
Así las cosas, la norma internacional de auditoría indica la responsabilidad expresa que tiene el auditor en una opinión (que para el estudio recae en el revisor fiscal) sobre los estados financieros de una empresa, puesto que dicha opinión debe ser basada en una evaluación de las conclusiones generadas a partir de la evidencia obtenida en la auditoría, y debe ser expresada de manera clara mediante un informe escrito, en el cual se describa la base en la que se sustenta (Ministerio de Comercio, Industria y Turismo, Decreto 2270 de 2019). En este sentido, en el presente artículo se abordan aspectos normativos que sustentan la modificación de la opinión en el dictamen de la revisoría fiscal y las implicaciones civiles y penales en las que incurre el revisor fiscal por la modificación de la opinión en su dictamen.

\section{PROBLEMA DE INVESTIGACIÓN}

La figura del revisor fiscal en Colombia es importante; algunas de sus funciones están descritas en el Código de Comercio en su artículo 207. Ahora bien, la problemática de este estudio se centra en analizar cuáles son las implicaciones civiles y penales en las que incurre el revisor fiscal por la modificación de la opinión en su dictamen; por el no cumplimiento a cabalidad de sus funciones, por desconocimiento de normas aplicables o por dádivas económicas. Así las cosas, se tiene que dicho incumplimiento de funciones ocasiona un daño económico y social que es valorado por los jueces, como autoridades jurisdiccionales que analizan la conducta y generan una multa o pena; se trata, pues, de sanciones contempladas en el Código de Comercio, el Código Penal y el Código Civil, producto de la responsabilidad que tiene el revisor fiscal al dar fe pública y considerarse, para estas sanciones, como servidor público.

\section{ESTRATEGIA METODOLÓGICA}

El estudio desarrolla una metodología analítica, a partir de la cual se identifican aspectos que se soportan en una exploración bibliográfica de investigaciones sobre las implicaciones civiles y penales en las que incurre el revisor fiscal por la modificación de la opinión en su dictamen, las implicaciones por el no cumplimiento de sus funciones, por el desconocimiento de normas aplicables o por dádivas económicas. En este aspecto, Gómez López (s. f.) define que la investigación analítica expone la investigación, la depuración y el tratamiento razonado de la información; proceso que en el estudio se lleva a cabo mediante la búsqueda de la información en libros, artículos en bases de datos y normatividad legal que soporten los análisis. Así mismo, Hurtado de Barrera (2012) considera que la investigación analítica constituye un proceso metódico de búsqueda de conocimiento a través de diferentes fuentes documentales, 
bases de datos y exploración bibliográfica, en pro de generar una interpretación sobre las implicaciones civiles y penales del revisor fiscal por la modificación de la opinión en su dictamen.

\section{RESULTADOS}

\section{Aspectos normativos que sustentan la modificación de la opinión en el dictamen de la revisoría fiscal}

El estudio inicia con la regulación que abarca las funciones del revisor fiscal como son las emitidas en el Código de Comercio y las leyes 222 de 2005, 964 de 2005 y 1762 de 2015, entre otras disposiciones normativas que son analizadas por Franco Ruiz (2020) así:

a. Inicialmente se aborda el Código de Comercio donde se deja claro las funciones del RF y otras acciones, en sus artículos 191 (el RF puede impugnar las decisiones de la asamblea), 193 (acción de indemnización por decisiones declaradas nulas que la puede ejercer el RF), 207 (funciones del RF), 209 (dentro de su informe el RF expresará si son adecuadas las medidas de control interno y para ello, deberá realizar una auditoría al control interno), 392 (el RF deberá notificar a la Superintendencia el resultado de la suscripción de acciones) y 489 ( El RF de una sociedad extrajera se sujetará a las disposiciones reglamentarias de Colombia).

b. La Ley 1762 de 2015, donde expone que el revisor fiscal (RF) deberá reportar a la Unidad de Información y Análisis Financiero (UIAF), operaciones sospechosas por lavado de activos.

c. La Ley 1778 de 2016, la cual le obliga al RF a denunciar actos de corrupción y la presunta realización de delitos contra la administración pública. Contra el patrimonio económico y delitos contra el orden económico y social.

d. Examinar lo adecuado del control interno, incluyendo el Sistema de Administración del Riesgo Operativo (SARO), Sistema de Administración del Riesgo de Lavado de Activos y Financiación del Terrorismo (SARLAF), Sistema de Autocontrol y Gestión del Riesgo de Lavado de Activos y Financiación del Terrorismo (SAGRLAFT), así como la conservación de libros y papeles.

e. La Ley 222 de 1995 expone algunas funciones anexas en su artículo 25 (la acción social de responsabilidad contra los administradores), artículo 47 (dictaminar sobre el informe de gestión - artículo que fue modificado en la Ley 603 de 2005-), artículo 48 (denunciar el incumplimiento al derecho de inspección). 
f. Ley 964 de 2005, en su artículo 45, donde se reglamenta que el RF deberá participar en reuniones del comité de auditoría.

g. Funciones en materia tributaria.

h. Denunciar las prácticas restrictivas de comercio (Franco Ruiz, 2020).

Lo anterior da cuenta de las múltiples funciones que atañe el ejercicio de la revisoría fiscal, porque cada una de ellas implica un trabajo arduo y de mucha responsabilidad hacia los grupos de interés.

En Colombia existe la figura del revisor fiscal que actúa bajo la Ley 43 de 1990, en cuyo su artículo 13 se indica que «(...) se requiere tener la calidad de contador público en los siguientes casos: 1. Por razón del cargo. Para desempeñar las funciones de revisor fiscal, auditor externo, auditor interno en toda clase de sociedades, para las cuales la ley o el contrato social así lo determinan (...)» (Congreso de la República, Ley 43 de 1990). En este sentido, el revisor fiscal será un contador público cuya función está determinada en las normas descritas en este estudio. Desde esta perspectiva se analiza el hecho de estar facultado para otorgar fe pública ante los grupos de interés por su condición de contador público, y la particularidad de autorizar con su firma un dictamen (Código de Comercio en su artículo 207), observando que el autorizar va más allá de una firma así:

Sinónimo de acreditar, consentir, aprobar. De ahí que, por la confianza en la labor que debe desarrollar, se la haya asignado tal deber para que el lector del mismo sepa que dicho estado conlleva una revisión de calidad de su contenido, y por tanto puede ser usado para la toma de decisiones. Sin embargo, tal requisito también lo adscribió a la indivisible exigencia de que ese testimonio (así debe entenderse) respecto de su contenido cierto, debe ir con un dictamen o informe sobre el mismo o los mismos, para que exprese el compromiso o responsabilidad que asume respecto de él, por el alcance de su actuar (Peña, 2011, pág. 121).

En este sentido, el emitir un dictamen por el RF implica una revisión detallada de lo expresado en el documento, por considerarse su contenido como «cierto»; situación que es respaldada por el Decreto 2270 de 2019, en la Norma Internacional de Auditoría (NIA) 700:

(...) la responsabilidad que tiene el auditor, al formarse una opinión sobre los financieros, de concluir sobre sí ha alcanzado una seguridad razonable de que los financieros en su conjunto están libres de incorrección material. La conclusión del auditor requerida por la NIA 700 tiene en cuenta la evaluación 
que el auditor realiza del efecto, en su caso, de las incorrecciones no corregidas sobre los estados financieros de conformidad con la presente NIA (Ministerio de Comercio, Industria y Turismo, Decreto 2270 de 2019, pág. 426).

Así las cosas, a pesar de que la NIA 700 enuncia la palabra «auditor», cabe recordar que el RF deberá acatar lo dispuesto en las NIA y, además de esto, tener en cuenta lo dispuesto en el Decreto 2270, para emitir su dictamen con una opinión modificada. Para el RF el modificar una opinión en su dictamen implica que algunos aspectos del dictamen anterior pueden variar, como se evidencia a continuación (Figura 1):

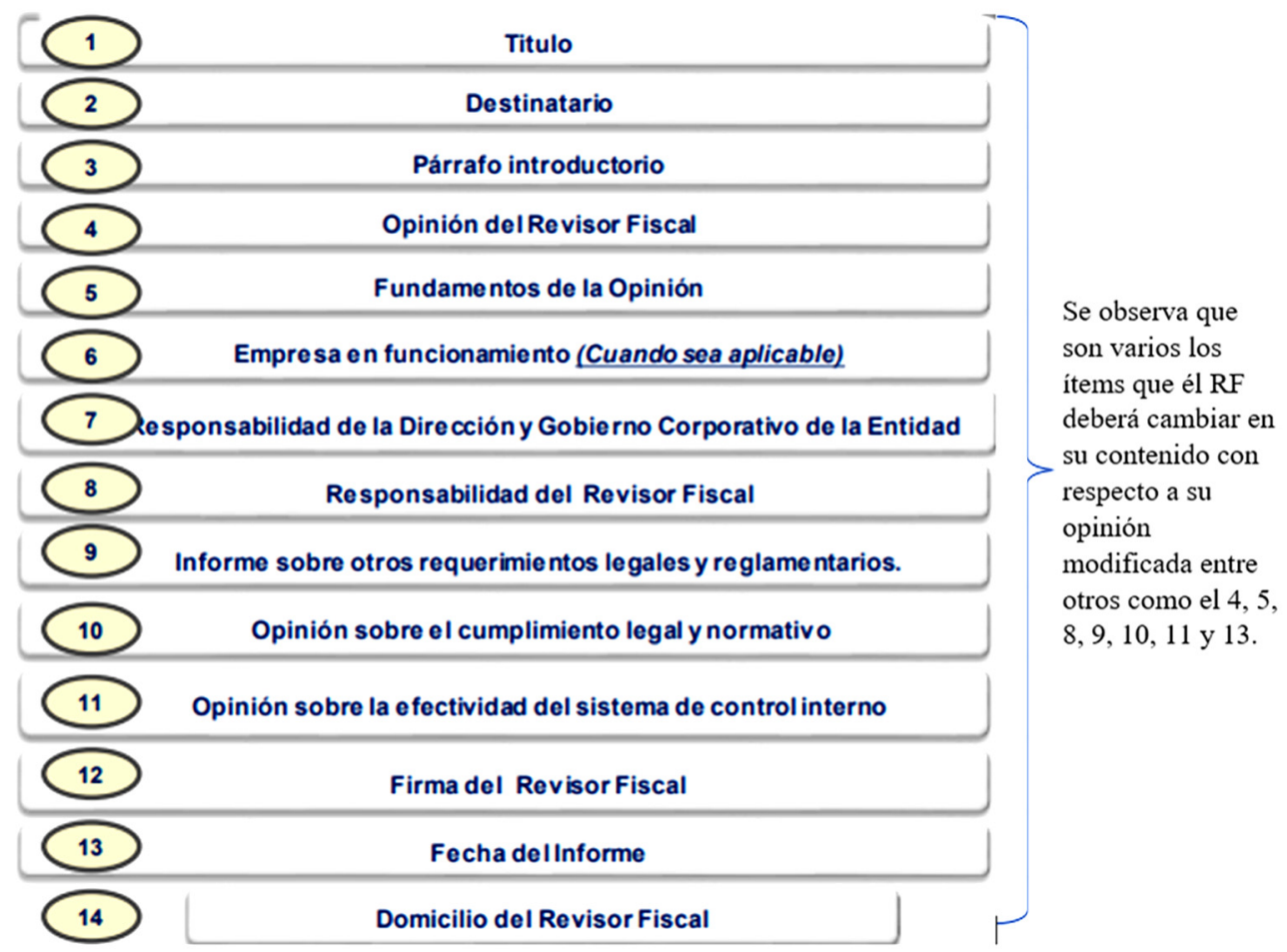

Figura 1. Modelo del informe del Revisor Fiscal, grupo 2-3.

Fuente: Consejo Técnico de la Contaduría Pública (2019). Adaptado por los autores.

Sin perjuicio de lo anterior, y atendiendo al Decreto 2270 de 2019, que implicó algunas modificaciones, se anexan dos aspectos a considerar en este modelo inicial, como es el párrafo de énfasis y otras cuestiones que se ubicarían después del fundamento de la opinión. 
En este contexto, el RF ya ha obtenido base suficiente y adecuada al emitir un dictamen, pero cuando requiera modificar su opinión, solo tiene tres alternativas: 1) presentar una opinión con salvedad, 2) presentar una opinión adversa o desfavorable y 3 ) abstenerse de emitir una opinión (también denominada denegación de opinión). Estas alternativas se analizarán atendiendo a la norma que regula el deber ser del ejercicio del RF en la organización a la cual le presta sus servicios (tabla 1 ).

\section{IMPLICACIONES CIVILES E IMPLICACIONES PENALES EN LAS QUE INCURRE EL REVISOR FISCAL POR LA MODIFICACIÓN DE LA OPI- NIÓN EN EL INFORME DE AUDITORÍA}

Puede ocurrir que el RF haya concluido que cambiará su opinión atendiendo a que tiene dos opciones: de una opinión modificada (con salvedad, abstención o adversa) pasa a una opinión no modificada o favorable; pero en esta situación se deberá aclarar en el párrafo cuestiones claves de auditoría (KAM en inglés y CCA en español), explicando que la opinión anterior se cambia debido a que la entidad ajustó lo indicado en los diferentes informes que presentó y demás comunicaciones, lo cual generó esa opinión inicial. Sin embargo, no es común que suceda esta situación, ya que las organizaciones prefieren subsanar todo lo indicado por la revisoría fiscal antes de que se emita su opinión.

Cuando esto ocurre no se generan implicaciones penales ni fiscales, puesto que las funciones del RF fueron observadas, acatadas y cumplidas, atendiendo al marco legal del ejercicio de la revisoría fiscal, en lo referente al aseguramiento donde se obliga a emitir un dictamen y en los aspectos de la fiscalización que obliga a la evaluación del control interno de la organización. Pero otro escenario diferente se observa cuando por otras situaciones, como fraudes (malversación de activos, corrupción, fraude financiero, entre otros), no fueron detectadas a tiempo o que, siendo detectadas, no fueron advertidas en el informe por intereses del RF, y por supuesto, con resultados poco favorables para los stakeholders. De esta manera, se generan las implicaciones penales y civiles que se explican a continuación:

\section{A. Implicaciones penales}

Este tipo de sanciones penales en ejercicio de la RF está determinado por los jueces penales y la Fiscalía General de la Nación. Es así como la Ley 599, en su artículo 34, expone tres tipos de penas así: penas principales (privativas de la libertad, prisión y multa), penas sustitutivas (prisión domiciliaria, arresto un fin de semana y sistema de vigilancia electrónica) y penas accesorias privativas 
Tabla 1. Opinión modificada y sus efectos en los grupos de interés.

\begin{tabular}{|c|c|c|c|c|}
\hline 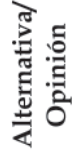 & ¿Cuándo se genera? & $\begin{array}{l}\text { Norma de } \\
\text { regulación }\end{array}$ & $\begin{array}{c}\text { Efecto ante los grupos de } \\
\text { interés }\end{array}$ & $\begin{array}{c}\text { Errores } \\
\text { generalizados } \\
\text { Sí/NO }\end{array}$ \\
\hline 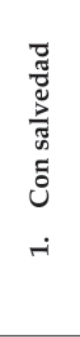 & $\begin{array}{c}\text { Se obtiene evidencia amplia y } \\
\text { suficiente. El RF concluye que } \\
\text { los errores identificados son } \\
\text { materiales, pero no } \\
\text { generalizados. Esta salvedad } \\
\text { contiene qué se encontró, qué } \\
\text { norma se incumplió, qué } \\
\text { requiere la norma que se } \\
\text { incumplió, y cuál es la } \\
\text { consecuencia para la empresa. }\end{array}$ & NIA 705-7 & $\begin{array}{c}\text { El identificar errores } \\
\text { materialmente importantes en } \\
\text { los EF le genera a los } \\
\text { stakeholders desconfianza en } \\
\text { cierta medida de las cifras que } \\
\text { se presentan, lo cual ocasiona } \\
\text { alertas de seguimiento a los } \\
\text { riesgos detectados. }\end{array}$ & No \\
\hline 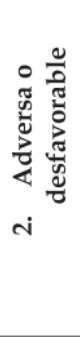 & $\begin{array}{c}\text { Cuando se accede a toda la } \\
\text { evidencia amplia y suficiente y } \\
\text { se detectan errores materiales } \\
\text { o de importancia relativa sobre } \\
\text { los EF, es decir, estas } \\
\text { incorrecciones son materiales y } \\
\text { generalizadas. }\end{array}$ & NIA 705-8 & $\begin{array}{c}\text { Una vez obtenida la evidencia } \\
\text { amplia y suficiente y se genere } \\
\text { una opinión adversa, } \\
\text { significaría que existen hechos } \\
\text { materiales y relevantes que } \\
\text { afectan gravemente las cifras; } \\
\text { por lo tanto, los grupos de } \\
\text { interés se verían afectados por } \\
\text { la situación que presenta la } \\
\text { empresa. }\end{array}$ & Sí \\
\hline \multirow[b]{2}{*}{ 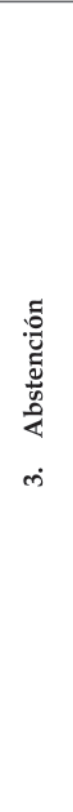 } & $\begin{array}{c}\text { Cuando el RF no pueda } \\
\text { obtener evidencia de auditoría } \\
\text { suficiente y adecuada en la que } \\
\text { basar su opinión y concluya } \\
\text { que los posibles efectos sobre } \\
\text { los EF de las incorrecciones no } \\
\text { detectadas, si las hubiera, } \\
\text { podrían ser materiales. }\end{array}$ & NIA 705-9 & $\begin{array}{c}\text { En caso de no obtener } \\
\text { evidencia válida y suficiente, } \\
\text { las incorrecciones podrían ser } \\
\text { materiales, lo cual genera } \\
\text { desconfianza a los grupos de } \\
\text { interés }\end{array}$ & Sí \\
\hline & $\begin{array}{c}\text { Existen circunstancias } \\
\text { extremadamente poco } \\
\text { frecuentes que supongan la } \\
\text { existencia de múltiples } \\
\text { incertidumbres, y el auditor } \\
\text { concluya que, a pesar de haber } \\
\text { obtenido evidencia de } \\
\text { auditoría suficiente y } \\
\text { adecuada en relación con cada } \\
\text { una de las incertidumbres, no } \\
\text { es posible formarse una } \\
\text { opinión sobre los estados } \\
\text { financieros debido a la } \\
\text { limitación en el alance. }\end{array}$ & NIA $705-10$ & $\begin{array}{c}\text { Las situaciones de } \\
\text { incertidumbre (múltiples) se } \\
\text { deberán explicar con } \\
\text { fundamentado en hechos que } \\
\text { «en cierta forma» den } \\
\text { tranquilidad en cuanto a las } \\
\text { cifras que se revelan, porque } \\
\text { se obtuvo evidencia suficiente } \\
\text { y adecuada. Sin embargo, a } \\
\text { juicio del RF, estas } \\
\text { incertidumbres pueden causar } \\
\text { un efecto acumulativo en los } \\
\text { estados financieros; por } \\
\text { ejemplo, lo que se vive a nivel } \\
\text { de riesgo de negocio, producto } \\
\text { de la pandemia. }\end{array}$ & Sí \\
\hline
\end{tabular}

Fuente: Ministerio de Comercio, Industria y Turismo. Decreto 2270 (2019), NIA 705. Adaptado por los autores. 
de otros derechos que inhabilitan el ejercicio de los derechos y funciones públicas y el ejercicio de la profesión, entre otras (Congreso de Colombia, Ley 599 de 2000, artículos 34, 35 y 36).

El RF puede cometer conducta punible que la Ley 599 en sus artículos 22 al 24 determina como: a) dolosa, en la cual, conociendo el hecho se quiere realizarlo, b) culposa, en la cual se analiza y prevé los resultados de la conducta, y c) preterintencional, en la que el resultado de la conducta es previsible y excede el propósito inicial. Tales conductas pueden ser cometidas por acción, cuando se realizan por violación de una norma que prohíbe esa acción, y omisión, cuando se genera porque no se actúa en posición de garante, conociendo el hecho; lo anterior, debido a que tipifican su conducta como si fuesen funcionarios públicos.

En este sentido, conviene recordar que se suelen mencionar como delitos al ejercicio de la RF la falsedad, el encubrimiento, el fraude procesal, el uso indebido de información privilegiada y la receptación (Pinilla Forero, 2010, pág. 517). A continuación, se exponen los principales delitos del Revisor Fiscal, según el Código Penal (tabla 2).

Cada uno de estos delitos implica que el RF no realizó su labor en debida forma o que obtuvo algún tipo de beneficio por no informar este delito. Por ello en el primer caso, se genera por falta de competencia, responsabilidad, atención a la normativa, actualización profesional entre otras, a pesar de que la Ley 43 en su artículo 37 lo exige, o como lo describe la revista Dinero (2017), existe exceso de funciones como se describen al inicio del artículo; de igual forma, algunos revisores fiscales conocen las implicaciones penales, pero acceden a cometer estos delitos.

\section{B. Implicaciones civiles}

La responsabilidad civil está encaminada a resarcir los daños económicos que por dolo o negligencia se ocasiona a la empresa o a los grupos de interés (Bermúdez Gómez, 2016). El RF presentará ante los organismos competentes, como lo expresa Hernández Aros, Caro \& Plazas Estepa (2017), que se debe contar con todas las herramientas jurídicas y demostrativas, además de que adquirió toda la evidencia suficiente y competente. Esto, para el estudio, representa una modificación de la opinión.

Para el estudio se tiene en cuenta lo estipulado en el artículo 211 del Código de Comercio y el artículo 42 de la Ley 222, que representan sanciones económicas, producto de los perjuicios ocasionados a la entidad y demás terceros que 
Tabla 2.

\begin{tabular}{|c|c|c|c|}
\hline Delito & De qué se trata este delito & $\begin{array}{c}\text { Código } \\
\text { Penal }\end{array}$ & Pena \\
\hline $\begin{array}{l}\text { Utilización } \\
\text { indebida de } \\
\text { información } \\
\text { privilegiada }\end{array}$ & $\begin{array}{l}\text { Cuando la información de una persona natural o } \\
\text { jurídica se utiliza para sacar provecho. Más aún } \\
\text { cuando el RF tiene a la mano toda la información } \\
\text { económico-financiera. }\end{array}$ & Art. 258 & $\begin{array}{l}\text { Uno (1) a tres (3) } \\
\text { años de prisión. }\end{array}$ \\
\hline $\begin{array}{l}\text { Falsedad en } \\
\text { documento }\end{array}$ & $\begin{array}{l}\text { Dentro de las funciones del RF se parte de la } \\
\text { atestación, donde se certifica la veracidad de los } \\
\text { hechos, y es allí donde puede otorgar falsedad } \\
\text { ideológica del documento que está emitiendo. }\end{array}$ & $\begin{array}{l}\text { Arts. 286- } \\
287\end{array}$ & $\begin{array}{l}\text { Sesenta y cuatro } \\
\text { (64) a ciento } \\
\text { cuarenta y cuatro } \\
\text { (144) meses de } \\
\text { prisión. }\end{array}$ \\
\hline $\begin{array}{l}\text { Captación no } \\
\text { autorizada de } \\
\text { ahorros }\end{array}$ & $\begin{array}{l}\text { Una de las funciones la contempla la Ley } 1762 \text { de } \\
\text { 2015, según la cual el RF deberá reportar, a la } \\
\text { UIAF, operaciones sospechosas por lavado de } \\
\text { activos; por lo tanto, deberá estar atento a este } \\
\text { tipo de situaciones. }\end{array}$ & Art. 316 & $\begin{array}{l}\text { Prisión de ciento } \\
\text { veinte }(120) \text { a } \\
\text { doscientos } \\
\text { cuarenta }(240) \\
\text { meses. }\end{array}$ \\
\hline $\begin{array}{l}\text { Pánico } \\
\text { económico }\end{array}$ & $\begin{array}{c}\text { El RF, al divulgar al público información inexacta } \\
\text { que afecte la confianza en el mercado de valores, } \\
\text { puede ocasionar el desplome en la Bolsa de } \\
\text { Valores de Colombia afectando a los grupos de } \\
\text { interés. }\end{array}$ & Art. 302 & $\begin{array}{l}\text { Prisión de treinta } \\
\text { y dos (32) a ciento } \\
\text { cuarenta y cuatro } \\
\text { (144) meses. }\end{array}$ \\
\hline $\begin{array}{l}\text { Violación de } \\
\text { reserva } \\
\text { industrial o } \\
\text { comercial }\end{array}$ & $\begin{array}{c}\text { El RF, al divulgar información de reserva } \\
\text { industrial y comercial, afecta gravemente a la } \\
\text { entidad, más aún cuando la Ley } 43 \text { de } 1990 \text { en su } \\
\text { artículo } 63 \text { obliga al contador público a guardar el } \\
\text { secreto profesional o confidencialidad en relación } \\
\text { con el ejercicio de la profesión contable (Congreso } \\
\text { de la República, Ley } 43 \text { de 1990, art. 63). }\end{array}$ & Art. 308 & $\begin{array}{l}\text { Prisión de dos a } \\
\text { cinco años y } \\
\text { multa de } 2000 \\
\text { salarios mínimos } \\
\text { legales } \\
\text { mensuales. }\end{array}$ \\
\hline $\begin{array}{l}\text { Utilización } \\
\text { indebida de } \\
\text { fondos } \\
\text { captados del } \\
\text { público }\end{array}$ & $\begin{array}{l}\text { Si la empresa destina de una forma incorrecta los } \\
\text { fondos captados del público, el RF deberá avisar } \\
\text { este hecho de manera temprana ante los } \\
\text { organismos competentes. }\end{array}$ & Art. 314 & $\begin{array}{l}\text { Treinta y dos (32) } \\
\text { a ciento ocho } \\
\text { (108) meses de } \\
\text { prisión. }\end{array}$ \\
\hline $\begin{array}{l}\text { Ocultamiento } \\
\text { de bienes } \\
\text { producto de } \\
\text { operaciones } \\
\text { ilícitas. }\end{array}$ & $\begin{array}{l}\text { Se tipifica este delito a partir del artículo } 323 \text { del } \\
\text { Código Penal, donde se expone dentro de las } \\
\text { funciones del RF que deberá examinar lo } \\
\text { adecuado del SARO, el SARLAF y el SAGRLAFT. }\end{array}$ & Art. 323 & $\begin{array}{l}\text { Prisión de } 10 \text { a } 30 \\
\text { años. }\end{array}$ \\
\hline $\begin{array}{l}\text { Fraude } \\
\text { procesal }\end{array}$ & $\begin{array}{l}\text { Por su calidad de RF, este puede inducir a un } \\
\text { empleado oficial a un error con el fin de obtener } \\
\text { un cierto resultado. }\end{array}$ & Art. 453 & $\begin{array}{l}\text { Prisión de cuatro } \\
\text { (4) a ocho (8) } \\
\text { años. }\end{array}$ \\
\hline $\begin{array}{l}\text { Delitos contra } \\
\text { medios de } \\
\text { pruebas y } \\
\text { otras } \\
\text { infracciones }\end{array}$ & $\begin{array}{l}\text { El RF puede incurrir en este delito cuando } \\
\text { encubre información, destruye o altera sobre un } \\
\text { asunto en particular. }\end{array}$ & Art. 454 & $\begin{array}{l}\text { Prisión de cuatro } \\
\text { (4) a doce (12) } \\
\text { años. }\end{array}$ \\
\hline
\end{tabular}

Fuente: Código Penal Colombiano. Ley 599 de 2000. Adaptado por los autores. 

por la modificación de la opinión en su dictamen

se generarían en caso de ser demostrado que el RF afectó a la organización por efecto de este cambio de opinión así:

- Artículo 157 del Código del Comercio, cuando el RF ocasiona perjuicios al ordenar, tolerar, hacer o encubrir falsedades cometidas en los balances.

- Artículo 211 del Código del Comercio, que explica la responsabilidad que tiene el RF con los grupos de interés por descuido o dolo en la observancia de sus deberes, y artículo 216, que estipula la multa por el incumplimiento de sus funciones o porque las realice de forma irregular, sin preservar las normas que acogen la profesión contable; multa que le será impuesta por las Supersociedades o la Superfinanciera.

- Artículo 222 del Código del Comercio, cuando el RF no se opone a que se desarrollen nuevas actividades pese a que la empresa se encuentra en disolución, excepto las autorizadas expresamente por la ley.

- Artículo 293 del Código del Comercio, cuando el RF suministra información que no es acorde a la realidad contable de la sociedad.

- Artículo 42 de la Ley 222, que aborda la obligatoriedad de presentar y difundir los estados financieros de la entidad, y en caso de no hacerse (sin justa causa) el RF responderá por el daño causado a quienes requieren de esta información para la toma de decisiones financieras.

Algunas multas contempladas en Código Penal traen consigo el valor económico mínimo y máximo que deberá cancelar el RF, por cambiar su opinión y afectar a los diferentes grupos de interés. Al analizar el Código Civil, se establecen dos elementos integrantes como el dolo y la culpa, respecto a los cuales el artículo 1902 establece el deber de indemnizar los daños y perjuicios causados por quienes en el cumplimiento de sus obligaciones incurrieren en dolo, negligencia o morosidad; en este sentido, cuando existe dolo el RF es responsable de todos los daños generados en su actuar, atendiendo a lo dispuesto por el Código Civil en su artículo 1616 (Congreso de la República, 1987).

En los aspectos económicos el Código Penal establece multas por lo siguiente:

- Utilización indebida de información privilegiada: multa de cinco (5) a cincuenta (50) salarios mínimos legales mensuales vigentes (SMLV).

- Captación no autorizada de ahorros: multa de ciento treinta y tres punto treinta y tres (133.33) a quince mil (15.000) salarios mínimos legales mensuales vigentes. 
- Pánico económico: multa de sesenta y seis punto sesenta y seis (66.66) a setecientos cincuenta (750) salarios mínimos legales mensuales vigentes.

- Violación de reserva industrial o comercial: multa de veintiséis punto sesenta y seis (26.66) a tres mil (3.000) salarios mínimos legales mensuales vigentes.

- Utilización indebida de fondos captados del público: multa hasta de cincuenta mil (50.000) salarios mínimos legales mensuales vigentes.

- Ocultamiento de bienes producto de operaciones ilícitas: multa de mil (1.000) a cincuenta mil (50.000) salarios mínimos legales mensuales vigentes.

- Fraude procesal: multa de doscientos (200) a mil (1.000) salarios mínimos legales mensuales vigentes.

- Delitos contra medios de pruebas y otras infracciones: multa de doscientos (200) a cinco mil (5.000) salarios mínimos legales mensuales vigentes (Código Penal colombiano. Ley 599 de 2000).

El actuar ético del revisor fiscal parte de la Ley 43 de 1990 en sus artículos 35 al 72, en los que, por ser un contador público, se exponen diferentes sanciones disciplinarias. Estas sanciones son contempladas y analizadas por la Junta Central de Contadores Públicos (JCC), la cual juzga las faltas del profesional contable en su ejercicio como inexactitud de revelación de información financiera, actuar como revisor fiscal en más de cinco (5) empresas, retención de documentación de la sociedad, firma de declaraciones tributarias estando en suspensión su tarjeta profesional por la JCC, no acatar los principios éticos de la profesión contable, entre otras. En esta forma, se observa que a noviembre de 2020 existían 1167 sanciones que generaron suspensión, 41 cancelaciones de la tarjeta profesional, 88 amonestaciones y 41 multas económicas (Junta Central de Contadores, 2020).

Al analizar el Código Civil, la culpa se origina cuando el RF no prevé el daño a ocasionar en la sociedad o al conocer el daño prevé que lo puede evitar. Aquella se origina por imprudencia, negligencia, impericia e inobservancia, y se encuentra dividida en a) culpa leve: se refiere a un descuido o falta de diligencia en la revisión de las cifras por parte del RF; b) culpa levísima: diligencia que el revisor fiscal comete al no cumplir con sus funciones según el Código de Comercio en su art 207, y c) culpa grave: considerada como dolo.

Por otra parte, el dolo consiste en la intensión positiva del RF de inferir injuria a propiedad de la empresa y contiene los elementos como: 
a) el volitivo, que se encuentra en el ámbito de los deseos del sujeto, motivados por estímulos originados en las necesidades de la contingencia humana; en este caso se puede generar por dádivas económicas que puede recibir el RF o la intención de alterar o causar daño a la empresa, y b) el cognitivo o intelectual, el cual se da en el ámbito de la consciencia del sujeto o bien de violaciones a deberes, como es el caso de las responsabilidades establecidas para el revisor fiscal.

\section{CONCLUSIONES}

Al contador público en ejercicio de la revisoría fiscal le atañen numerosas funciones contenidas en normas como el Código De Comercio y las leyes 222 de 2005, 964 de 2005 y 1762 de 2015 En efecto, al ser analizadas, dichas normas y leyes contienen deberes y obligaciones que deben ser acatadas por el RF como órgano fiscalizador que deberá responder cuando exista de su parte negligencia o dolo ante los diferentes grupos de interés, lo cual representa sanciones de tipo civil y penal que implican un juzgamiento por parte de las autoridades jurisdiccionales con multas y penas que serán interpuestas por los directamente afectados.

Se ha considerado las implicaciones civiles del revisor fiscal, expuestas en el Código Civil colombiano, las cuales abordan elementos como la culpa (leve, levísima) y el dolo, la negligencia o la morosidad, que requieren una indemnización por los daños y perjuicios causados en el incumplimiento de sus obligaciones (que para nuestro estudio es el cambio de una opinión en su dictamen de forma injustificada). Así, la consecuencia del actuar culposo del RF implica diferentes sanciones económicas, según los hechos, las circunstancias y las evidencias presentadas ante el juez, de manera que aquel se hace responsable de todos los daños ocasionados y, paralelo a ello, afecta de forma directa lo disciplinario impuesto por la Junta Central de Contadores.

Las implicaciones penales son expuestas en el Código Penal de Colombia; estas abarcan desde prisión entre uno (1) y tres (3) años por el delito de utilización indebida de información privilegiada, que corresponde a la mínima condena, hasta pena de prisión de entre 10 y 30 años por el delito de ocultamiento de bienes producto de operaciones ilícitas. Esta situación debe ser analizada por el revisor fiscal al ejercer su cargo, ya que entre sus funciones está la de emitir un dictamen (que contiene su opinión) que debe ser veraz, auténtico y resultado del cumplimiento de sus deberes, puesto que este informe otorga credibilidad y argumentos válidos ante terceros que requieren de él para la toma de decisiones. 


\section{REFERENCIAS}

Bermúdez Gómez, H. (2016). Revisoría fiscal Órgano social. Bogotá: Ediciones de la U.

Bermúdez Gómez, H. (2020). Introducción a la responsabilidad del revisor fiscal. Recuperado el 20 de 10 de 2020, de https:/ / www.javeriana.edu.co/ personales/hbermude/ ensayos/ResponsabilidadRF.pptx

Congreso de Colombia. Ley 599 de 2000. Por la cual se expide el Código Penal. Obtenido de http://www.secretariasenado.gov.co/senado/basedoc/ley_0599_2000.html

Congreso de la República. (1987). Código Civil Colombiano [CCC]. Ley 57 de 1887. Obtenido de https:/ / leyes.co/codigo_civil.htm

Congreso de la República. Ley 43 de 1990. Artículo 13. Por la cual se adiciona la Ley 145 de 1960, reglamentaria de la profesión de Contador Público y se dictan otras disposiciones. Obtenido de: https://www.mineducacion.gov.co/1621/articles104547_archivo_pdf.pdf

Congreso de la República. Ley 43 de 1990. Por la cual se adiciona la Ley 145 de 1960, reglamentaria de la profesión de Contador Público y se dictan otras disposiciones. Obtenido de https:// www.jcc.gov.co/images/pdfs/normatividad/leyes/LEY\%2043\%20 DE\%201990.pdf

Consejo Técnico de la Contaduría Pública. (1 de 08 de 2019). Revisoría Fiscal para pequeñas entidades. Obtenido de Parte I. Tipos de Dictamen: https:/ / www.ctcp.gov. $\mathrm{co} /$ publicaciones-ctcp/orientaciones-tecnicas/orientacion-revisoria-fiscal-partei-agosto-1-2019

Franco Ruiz, R. (2020). Revisoría Fiscal, ¿Qué debe hacer?, ¿Cómo debe hacer? Obtenido de https:/ / www.youtube.com/watch?v=cb2vwEf-49Q

Gómez López, R. (s. f.). Evolución Científica y Metodología de la Economía: Escuelas de Pensamiento. Obtenido de https:// www.eumed.net/cursecon/libreria/rgl-evol/ index.html

Hernández Aros, L., Caro, N., \& Plazas Estepa, R. (19 de 09 de 2017). El proceso penal frente al estándar denominado «más allá de toda duda razonable»: un análisis a partir del rol del contador público. La Republicana, 149-166. doi: http:// ojs.urepublicana.edu.co/index.php/revistarepublicana/article/view/410

Hurtado de Barrera, J. (2012). Metodología de la investigación. Guía para la comprensión holística de la ciencia. Fundacite-SYPAL. Caracas.

Junta Central de Contadores. (2020). Lista de Contadores sancionados. Obtenido de https:/ /sgr.jcc.gov.co:8181/apex/f?p=119:1:0: 

por la modificación de la opinión en su dictamen

Ministerio de Comercio, Industria y Turismo. (Decreto 2270 de 2019). NIA 705. Recuperado el 30 de 06 de 2020, de Por el cual «Se compilan y actualizan los marcos técnicos de las Normas Información para el Grupo 1 y de las Normas de Aseguramiento de Información (...)»: https:/ / dapre.presidencia.gov.co/normativa/normativa/DECRETO\%202270\%20DEL\%2013\%20DICIEMBRE\%20DE\%202019.pdf

Organización Internacional de Estandarización. (ISO 26000, 2010). Obtenido de https:/ /www.iso.org/files/live/sites/isoorg/files/archive/pdf/en/iso_26000_project_ overview-es.pdf

Peña, J. (2011). Revisoría fiscal (2. a ed.). Bogotá: Ecoe Ediciones. Recuperado el 20 de 05 de 2020, de http://www.ebooks7-24.com/?il=171\&pg=135

Pinilla Forero, J. D. (2010). La revisoría fiscal: un modelo de fiscalización integral permanente con enfoque de metacontrol organizacional. Grupo Editorial Nueva Legislación SAS. Obtenido de https:// bbibliograficas.ucc.edu.co:4058/es/ereader/ucc/70828? page $=1$

Revista Dinero. (03 de 02 de 2017). Revisores fiscales al banquillo: ¿Ciegos o con exceso de funciones? Obtenido de https:/ / www.dinero.com/edicion-impresa/caratula/articulo/el-papel-de-los-revisores-fiscales-en-escandalos-empresariales/242468 